\title{
THE INTRAFAMILIAL TRANSMISSION OF RHEUMATOID ARTHRITIS-VI
}

\section{ASSOCIATION OF RHEUMATOID ARTHRITIS WITH SEVERAL TYPES OF STATUS INCONSISTENCY}

\author{
Stanislav V. Kasl, Ph.D. and Sidney CobB, M.D.
}

Institute for Social Research and The Department of Psychology, The University of Michigan, Ann Arbor, Michigan

(Received 21 December 1967; in revised form 26 August 1968)

IN THIS report we shall examine the findings which relate an interview-based index of rheumatoid arthritis (RA) to diverse forms of status inconsistency. We shall begin by presenting briefly the theoretical rationale which justifies our interest in this rather complex concept and a few studies will be cited to illustrate its empirical usefulness. Next, the measurement procedures will be described in some detail. In the presentation of results, we shall be concerned with three types of status inconsistency: as a variable describing the respondent's parents' marriage, as describing the respondent himself, and as characterizing the respondent's own marriage.

\section{THE THEORY}

The long-standing interest of social scientists in status variables has led to two kinds of orientations or emphases. The more traditional approach has been either to examine separately such status indicators as education, occupation, income, and racial-ethnic origin, or to study them in a combined index of social class or social status. The theoretical underpinnings of this approach are given by the symbolic interactionist position of COOLEY and MEAD $[1,2]$ and by role theory $[3,4]$. Basically, it is asserted that an individual's rank or position on a status dimension is important because it partly determines certain expectations about his behavior. Specifically, an individual's rank affects his expectations about the behavior of others towards him, his expectations of himself, and others' expectations of him. The total pattern of these interacting expectations will influence the individual's concept of himself and the concept others have of him, that is, his self-identity and public identity, respectively $[5,6]$.

The second approach to status variables emphasizes the congruence or discrepancies among them [7-9]. The central idea is that if an individual's rank on 1 status dimension is out of line with his rank on another, then according to role theory, there is the strong possibility of conflicting expectations about the behavior of others and 
uncertainty about appropriateness of one's own behavior. This in turn, should lead to role conflict, unsatisfactory social relationships, social ambiguity, unstable or inconsistent self-identity [10-12] as well as attempts to achieve a better status equilibrium [13]. In short, when there is an inconsistency among the several status indicators which are used to characterize an individual, the individual is presumed to be under stress which is then predicted to have adverse effects on his physical and mental health.

It should be apparent that out of the basic idea of status inconsistency-examining the discrepancy in ranks on a pair of status dimensions-one can generate a typology which indicates what individuals or units are involved for whom 2 or more status ranks are being measured and related to each other. Thus status inconsistency can be a property of:

(a) A single individual, such as when we are comparing education of the family head with his occupation.

(b) A 'natural' pair of individuals, such as comparing husband's education with wife's education. (When such a pair of individuals spans two generations, as in the case of father's occupation and son's occupation, the usual term 'mobility' is certainly appropriate.)

(c) A group of interacting individuals, such as Air Force crews [14] or taskoriented groups $[15,16]$.

(d) A collection of individuals, such as those belonging to the same occupational groups [17].

Given then the fact that there are at least four distinguishable types of status inconsistency, and that, moreover, a plethora of terms exist labelling the same phenomenon-status incongruence, discrepancy, imbalance, equilibrium, crystallization and inconsistency - the present writers propose the following terminology: (a) Status incongruence as a property of a single individual; (b) Status discrepancy as a property of a pair of individuals; (c) Status equilibrium as property of an interacting group; (d) Status crystallization as property of a collective, such as an occupational group. That still leaves status inconsistency as a general term representing all of the subtypes (status equilibrium and crystallization are not a concern of this paper).

It will be readily apparent, when the findings of this report are presented, that one need not study only the effects status inconsistency has on the same individual or individuals on whom the inconsistency is assessed. One can examine, for example, the effects of husband's status incongruence on the wife's health or one can investigate intergeneration effects, i.e., the effects of father-mother status discrepancy on the health of the offspring. In this study, the presence of RA will be related to: $(a)$ parental status incongruence and discrepancy; $(b)$ respondent's own incongruence; (c) status discrepancy in the respondent's marriage, and $(d)$ the incongruence of respondent's spouse.

Most findings on status inconsistency are concerned with intragenerational effects of incongruence and equilibrium. Individuals whose status indices are incongruent report more psychophysiological symptoms [11, 18], have more rheumatoid arthritis [19], are more likely to be liberal in their politcal attitudes [9], and to be dissatisfied with the power distribution in our society [20], and tend to show less social participation [21]. Members of interacting workgroups show greater mutual trust, intimacy, congeniality and agreement when they are characterized by high status equilibrium 
[14, 16]. Negative evidence, however, is reported by KORNHAUSER [22] who studied men coming from a rather restricted range of occupations and found no relationship between an index of mental health and several measures of incongruence.

Notable are also a few studies which pay attention to the direction of status incongruence. Thus, some writers have interpreted high education-low occupation incongruence as a discrepancy between aspirations and achievement and have related such incongruence to job dissatisfaction [23] and to higher rates of first admissions to hospital for schizophrenia among urban Negroes [24]. In one study [18] the direction of status incongruence was important in 1 of the 2 alternative regression models which could be chosen.

The effects of parental status discrepancy on the offspring have also been investigated. Several studies report that when mother's education (or occupational status prior to marriage) exceeds father's, the offspring's attained or aspired education will be higher [25-27]. In these studies, however, the effects of vertical status do not seem to have been fully eliminated. A recent report indicates that parental status incongruence and discrepancy can have strong effects on the physical and mental health of the adult offspring [28].

\section{METHODS}

The general design of the study, the nature of the sample, the methods of measuring rheumatoid arthritis have been given in the first 2 papers of this series. In this section we shall describe the development of the various status incongruence and discrepancy measures.

The basic demographic data collected from the respondents included: father's education and occupation, mother's education, respondent's own education and perceived social class. The last variable was measured by a single question: Now tell me which one of the following social classes would you say you belonged to at the present time? The fixed alternatives were upper class, upper middle class, middle class, lower middle class, upper working class, and lower working class.

In addition, the male respondents gave their occupation and income; 63 per cent of the female respondents were non-working housewives. The occupations of the respondents and of the respondents' fathers were recoded according to the Duncan code of occupational prestige [29].

In constructing the parental status incongruence and discrepancy measures, the three status variables - father's and mother's education and father's occupationwere dichotomized at approximately the median and paired as follows: mother's education with fathers' education, mother's education with father's occupation, and father's education with father's occupation. This resulted in 3 two-by-two tables, status discrepancy (in the first 2 tables) and status incongruence (in the third table) were indicated whenever one of the paired variables was above the median, while the other was below, and vice versa. A total index was also constructed by simply adding up for each respondent the discrepancies and incongruence which characterized his (her) parents' marriage. Clearly, the range of possible scores on this total index of parental status incongruence and discrepancy is from zero to three. Hereafter, we shall refer to this total measure as the 'parental status stress index'.

The following data are important in understanding the 'parental status stress index' and its components: (1) The distribution of scores on the index is unrelated to: (a) 
parents' education; (b) father's occupation; $(c)$ respondent's sex, age, and education; (d) the distinction between National and Clinic samples. (2) The three components of the total index are positively intercorrelated. (3) There were 34 pairs of siblings who gave independent and complete data on their parents; the amount of agreement between the 2 sets of index scores is reflected by a Pearson correlation of 0.79 (the gamma value was also 0.79). For further detail regarding this index, see KASL and CoBB [28].

It is also worth noting that in the present study, rates of RA among the men and the women were not related to parents' education or father's occupation.

Three salient characteristics of the 'parental status stress index' deserve comment: it is crude, it is a conglomerate summary measure, and it disregards the direction of the status incongruence or discrepancy. The crudeness can be justified on the grounds that the original data did not suggest a much finer classification scheme. For example, over 45 per cent of the subjects listed their father's occupation as farmer, thus ruling out any refined classification with regard to occupational prestige. The conglomerate nature of the total index can be justified on the grounds that: $(a)$ the components are positively intercorrelated; and $(b)$ all analyses done separately on the three component indices yielded similar results [28]. The disregard of the direction of status incongruence or discrepancy has a similar justification: separate analyses which kept track of the direction (e.g., Fa. Educ. $>$ Mo. Educ. as opposed to Fa. Educ. $<$ Mo. Educ.) made little difference in the final outcome.

Let us now turn to the status incongruence indices which were constructed to characterize the respondents themselves. As we shall see, somewhat more refined indices are possible. Moreover, the direction of incongruence will be retained. For the male respondents, three incongruence measures were constructed from pairing education, occupation, and perceived social class with each other. For the women, the majority of whom did not work outside of the home, only 1 index was constructed: that which resulted from pairing education and perceived social class.

In order to characterize individuals on status incongruence, a scatter plot was drawn such that the reference axes represented the two status variables being paired and the points were each subject's scores on them. A broad band of points along the diagonal(or along the regression line) indicated subjects whose paired status variables were congruent. The remainder, the incongruent subjects were further classified according to direction of incongruence, e.g., education > occupation or occupation > education.

Let us finally discuss the various status discrepancy measures which were constructed in order to characterize the marriage of our respondents. Six pairs of variables were examined in order to derive indices of status discrepancy: (1) Husband education vs. wife education; (2) Husband occupation vs. wife education; (3) Husband perceived social class vs. wife education; (4) Husband education vs. wife perceived social class; (5) Husband occupation vs. wife perceived social class; and (6) Husband perceived social class vs. wife perceived social class.

In the case of husband vs. wife education, 3 degress of discrepancy were recognized: (a) no discrepancy: the spouses have same number of years of education; $(b)$ moderate discrepancy: 1 spouse has $1-3$ yr more education than the other; $(c)$ high discrepancy: 1 spouse's education exceeds the other's by 4 or more years. (The few respondents who had $5 \mathrm{yr}$ of education or less were all categorized together as having '5-yr'; this wasdone 
because it was assumed that the difference between 2 and $5 \mathrm{yr}$ of education is not as important as that between 12 and $16 \mathrm{yr}$.) In the case of husband vs. wife perceived social class, discrepancy was indicated when they differed by more than 1 social class category. For the other 4 discrepancy measures, the procedure of drawing a scatter plot was again followed. Those cases within a broad band of points along the diagnonal (or along the regression line) were designated as non-discrepant marriages, while the remainder were the discrepant marriages, e.g. husband occupation $>$ wife education $>$ husband occupation.

The 6 possible instances of discrepancy were summed together to yield 2 total marriage discrepancy indices: one ignoring the direction of discrepancy and the other keeping track of which spouse was scoring higher on a set of paired status variables. However, keeping track of the direction of discrepancy-whether on the individual indices or on his total measure-proved unnecessary as it made no difference in relating it to RA in marriage. This paper will therefore be primarily concerned with non-directional marriage discrepancy (we shall return to this point in the presentation of results).

In the analysis of the marriage discrepancy indices, data were available on 97 marital pairs. These marriages were classified according to presence-absence of RA and/or peptic ulcer (henceforth referred to as PU; for details of classification of respondents on the 'ulcer index' and for more information about these marriages, the reader is referred to the seventh paper in this series). There were: (1) 41 marriages where both husband and wife were "healthy" (no RA and no PU); (2) 28 marriages where the wife had RA but husband was healthy; (3) 11 marriages where husband had RA and wife was healthy; and (4) 17 "miscellaneous" marriages, such as wife RA-husband PU, or husband PU-wife healthy.

In the data to be presented below, we shall also be concerned with the effects of husband's own status incongruence on the wife. For this purpose we shall use 3 indices judged most relevant to wife's concerns: husband's occupation vs. his education (same as before), his income vs. his education, and his income vs. his occupation. A total index, summing the 3 components, will also be used.

In summary, then, we are dealing with the following measures: (1) Three separate measures of status discrepancy and incongruence, describing parents marriage: 'Mo. Educ. vs. Fa. Educ., Mo. Educ. vs. Fa. Occup., and Fa. Educ. vs. Fa. Occup. A summary measure combining these 3, the 'parental status stress index', is also used. All the indices are related to presence-absence of RA in the adult offspring, the respondent. (2) A number of status incongruence measures based on respondent's 'own' status variables. For the men, the measures are: Educ. vs. Occup., Educ. vs. Perceived social class, and Occup. vs. Perceived social class; for the women, there is only 1 measure: Educ. vs. Perceived social class. All the indices are related to presenceabsence of RA in the respondent. (3) A number of status discrepancy measures characterizing the respondents' marriage and generated by pairing husband's and wife's status variables. A summary index is also used. These measures arc rclatcd to presence-absence of RA (and PU) in the marriage. (4) Three status incongruence measures characterizing the husband, and a summary index. These measures are related to presence-absence of $\mathrm{RA}$ in the wife.

In order to explore the generality of the effects of the diverse status inconsistency indices mentioned above, a second dependent variable was chosen: the respondent's 
reported 'self-esteem (adult)'. This is an eight item index in which the respondents evaluate themselves and their performance in a number of typical social roles, such as spouse, parent, provider or housekeeper, etc.; the items are different for males and for females. (For more information about this scale, see the fifth paper in this series.) In this way, a parellel set of analyses will be run and the effects of status inconsistency on RA can be compared with its effects on this psychological variable. And because of the grounding of status inconsistency theory in role theory and because of specific predictions about interference with role performance, 'self-esteem' seems to be the most suitable psychological variable in this type of comparison.

Before turning to the presentation of results, let us first consider an important methodological point. In examining the correlates of status inconsistency, we must make sure that effects of vertical status per se (e.g., education alone or occupation alone) have been ruled out. Such effects can be safely ruled out provided that the dependent variables and/or the status inconsistency indices are not correlated with the individual status variables. An examination of our data reveals that: (1) Presenceabsence of RA in respondents is unrelated to father's and mother's education, father's occupation, or own education, occupation, income, and perceived social class. (2) Marriages which differ on presence-absence of RA or PU in either spouse show no differences on average education and perceived social class of the spouses, or on husband's occupation and income. (The absence of status effects is not a 'finding' but reflects rather the constraints inherent in the design of this study.) (3) Self-esteem shows only trivial association with the several status variables. (4) The various status inconsistency indices reveal only an occasional, weak association with a particular status variables. Moreover, the direction of the association varies: sometimes the status consistent respondents are higher on a status variable and sometimes the status inconsistent respondents are. It may thus be concluded that, given the absence of associations with the dependent variables and the occasional, weak, and not systematic associations with the status inconsistency indices, the possible effects of vertical status per se are ruled out.

\section{RESULTS}

Table 1 presents the major data relating the 3 types of parental status inconsistency and the summary measure to rates of RA among adult offspring (who are the respondents). We can see that among women, RA is morc frcquent if their parents show greater status incongruence and discrepancy. The association of RA with the 'total index' is notably linear and rather strong. Among men, whose overall prevalence rate is less than one third of the rate for women, there is a weak, unstable trend in the opposite direction. The sex difference is clearly significant.

An examination of the peptic ulcer (PU) cases in men revealed no association with the 'total parental status stress index'.

Table 2 gives the findings which relate the respondents' self-esteem to parental status discrepancy and incongruence. (The measures of association, gamma and Tau, have been discussed in the 4th paper of this series.) For the healthy men and women, lower self-esteem is found among those whose parents' marriage was status inconsistent; this relationship holds for the total index and for all the components (with one exception, Fa. Educ. vs. Fa. Occup. among women). Men with RA and/or PU show a reversal of this relationship: those coming from families where parents' 


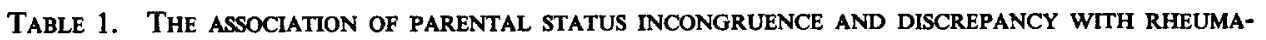
TOID ARTHRITIS IN ADULT MALE AND FEMALE OFFSPRING

\begin{tabular}{|c|c|c|c|c|c|c|}
\hline \multirow{2}{*}{$\begin{array}{l}\text { Index of parental status } \\
\text { incongruence and discrepancy }\end{array}$} & \multicolumn{3}{|c|}{$\begin{array}{l}\text { Percentage of sons with } \\
\text { rheumatoid arthritis }\end{array}$} & \multicolumn{3}{|c|}{$\begin{array}{l}\text { Percentage of daughters with } \\
\text { rheumatoid arthritis }\end{array}$} \\
\hline & $(N)$ & $(\%)$ & ( $p$-value) & $(N)$ & $(\%)$ & ( $p$-value) \\
\hline $\begin{array}{l}\text { Mo. Educ. vs. Fa. Educ. } \\
\text { Consistent } \\
\text { Discrepant }\end{array}$ & $\begin{array}{l}66 \\
76\end{array}$ & $\begin{array}{r}12 \\
8\end{array}$ & n.s. & $\begin{array}{l}58 \\
62\end{array}$ & $\begin{array}{l}24 \\
47\end{array}$ & $<0.005$ \\
\hline $\begin{array}{l}\text { Mo. Educ. vs. Fa. Occup. } \\
\text { Consistent } \\
\text { Discrepant }\end{array}$ & $\begin{array}{l}65 \\
79\end{array}$ & $\begin{array}{r}15 \\
6\end{array}$ & $<0.05$ & $\begin{array}{l}50 \\
73\end{array}$ & $\begin{array}{l}24 \\
45\end{array}$ & $<0.01$ \\
\hline $\begin{array}{l}\text { Fa. Educ. vs. Fa. Occup. } \\
\text { Congruent } \\
\text { Incongruent }\end{array}$ & $\begin{array}{l}90 \\
53\end{array}$ & $\begin{array}{r}12 \\
9\end{array}$ & n.s. & $\begin{array}{l}69 \\
46\end{array}$ & $\begin{array}{l}29 \\
50\end{array}$ & $<0.025$ \\
\hline $\begin{array}{l}\text { Total Parental status stress } \\
\text { index } \\
\text { Low } \\
\text { Intermediate } \\
\text { High }\end{array}$ & $\left.\begin{array}{l}49 \\
70 \\
20\end{array}\right\}$ & $\begin{array}{r}16 \\
7\end{array}$ & $<0.05$ & $\begin{array}{l}40 \\
55 \\
19\end{array}$ & $\begin{array}{l}20 \\
40 \\
68\end{array}$ & $<0.001$ \\
\hline
\end{tabular}

marriage was status inconsistent tend to have somewhat higher self-esteem. Women with RA show this reversal of relationship for only one component, Mo. Educ. vs. Fa. Educ., and otherwise tend to resemble the healthy women. At present, the writers can offer no sound explanation of this reversal for the men with RA and/or PU.

Table 3 presents the data which relate the respondents' own status incongruence to presence vs. absence of RA. For women, only 1 index of status incongruence was constructed (as in Table 1). The findings in Table 3 are rather clearcut: there appears no association between RA and status incongruence. An examination of the PU cases in men also failed to detect a significant association with status incongruence. Construction of additional incongruence indices using the man's income produced the same lack of association. Taking into consideration the direction of the various types of status incongruence did not alter this conclusion.

When we turn to Table 4 we see that the different types of status incongruence do show a relationship with self-esteem. The table is set up so that one can examine the results for the healthy subjects and the subjects with RA and/or PU separately. The mean scores on the self-esteem scale are given for all the groups so that the reader can determine the direction of the association represented by the various gamma and Tau values. The findings may be summarized as follows: (1) Subjects whose education is unduly high (when paired with occupation or perceived social class) are consistently the lowest on self-esteem. This holds for both sexes, and the healthy as well as the RA and/or PU respondents. The healthy men whose occupation is unduly high in relation to perceived social class are also the lowest on self-esteem. (2) The congruent healthy men are always the highest on self-esteem. Among the men with RA and/or PU, it is the incongruent man with perceived social class or occupation unduly high who tends to be the highest on self-esteem. (Here, however, the number of cases involved is very small.) (3) The women, whether they have RA or not, tend to be 


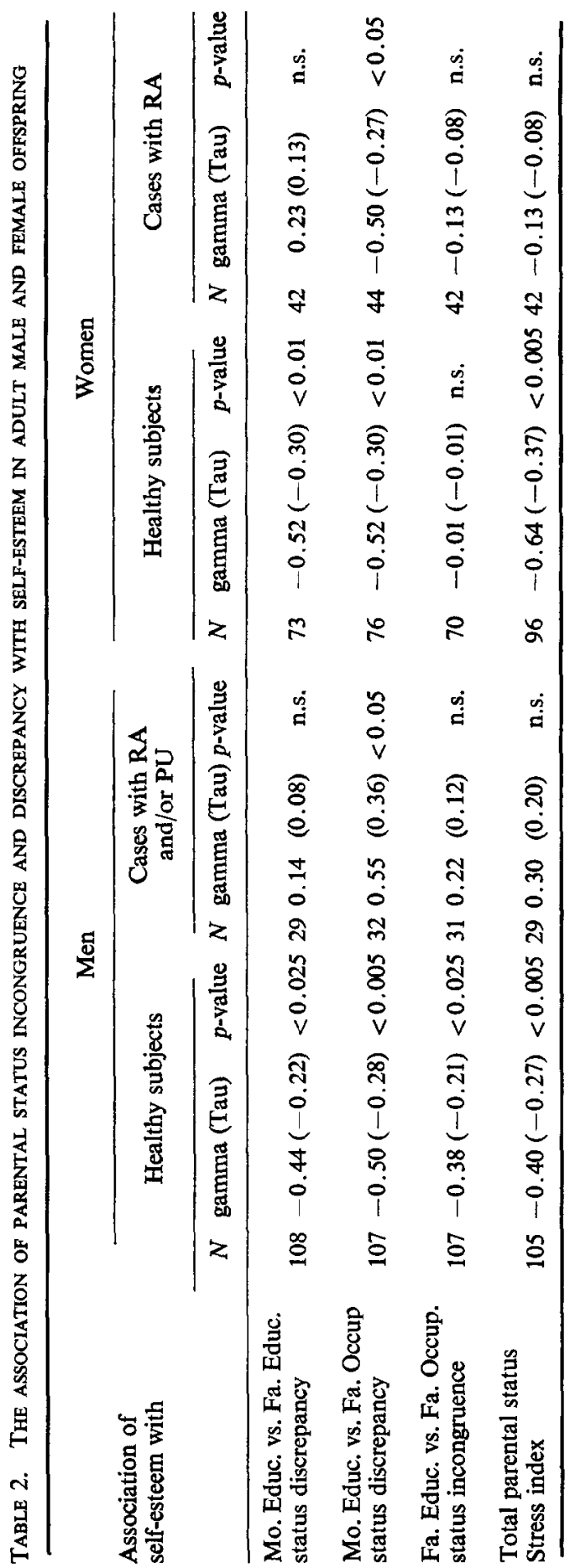


TABLE 3. THE ASSOCIATION OF RESPONDENTS' STATUS INCONGRUENCE WTTH RHEUMATOID ARTHRITIS

\begin{tabular}{|c|c|c|c|c|c|}
\hline \multirow{3}{*}{\multicolumn{2}{|c|}{ Type of status incongruence }} & \multirow{2}{*}{\multicolumn{2}{|c|}{$\begin{array}{c}\text { Men } \\
\text { Percentage of } \\
\text { cases with RA }\end{array}$}} & \multirow{2}{*}{\multicolumn{2}{|c|}{$\begin{array}{c}\text { Women } \\
\begin{array}{c}\text { Percentage of } \\
\text { cases with RA }\end{array}\end{array}$}} \\
\hline & & & & & \\
\hline & & $N$ & $(\%)$ & $N$ & $(\%)$ \\
\hline & Congruent & 78 & 13 & 91 & 31 \\
\hline \multirow{3}{*}{$\begin{array}{l}\text { Education vs. } \\
\text { perceived social } \\
\text { class (PSC) }\end{array}$} & $\begin{array}{l}\mathrm{PSC}> \\
\text { education }\end{array}$ & 20 & 10 & 18 & 44 \\
\hline & $\begin{array}{l}\text { Education > } \\
\text { PSC }\end{array}$ & 49 & 8 & 40 & 33 \\
\hline & Congruent & 79 & 11 & & \\
\hline \multirow{3}{*}{$\begin{array}{l}\text { Occupation vs. } \\
\text { perceived social } \\
\text { class (PSC) }\end{array}$} & $\begin{array}{l}\text { PSC > } \\
\text { occupation }\end{array}$ & 34 & 9 & & \\
\hline & $\begin{array}{l}\text { Occupation > } \\
\text { PSC }\end{array}$ & 31 & 10 & & \\
\hline & Congruent & 91 & 12 & & \\
\hline \multirow[t]{2}{*}{$\begin{array}{l}\text { Education vs. } \\
\text { occupation }\end{array}$} & $\begin{array}{l}\text { Occupation }> \\
\text { education }\end{array}$ & 33 & 9 & & \\
\hline & $\begin{array}{l}\text { Education > } \\
\text { occupation }\end{array}$ & 23 & 9 & & \\
\hline
\end{tabular}

like the men with RA and/or PU: the PSC> Education group is the highest on selfesteem, while the congruent subjects are intermediate.

Let us now turn to an examination of status variables which characterize a pair of individuals, i.e., status discrepancy between husband and wife. Six pairs of status variables were examined; moreover a 'total status discrepancy index' for each marriage was also constructed. Findings are presented on 97 marital pairs (see the Methods section where the indices and the 4 types of marriages are described).

Table 5 presents the findings for educational discrepancy and Table 6 gives the data for the other 5 discrepancy indices. The education data are presented separately for two reason: (1) It is assumed to be the most important type of discrepancy, one which is perhaps most "visible" to the spouses and to those around them. (2) Education can be measured more easily and more precisely than occupational status or perceived social class. The statistical comparisons carried out in Tables 5 and 6 are all those which could be of any interest: the healthy group is compared separately with each of the 3 disease groups, with the 2 RA groups combined, and with all three disease groups combined.

The findings in Tables 5 and 6 may be summarized as follows: (1) Group C, 'husband RA and wife healthy', tends to have the most instances of status discrepancy, while Group A, the healthy spouses, tends to have the least. Group D miscellaneous disease combinations, has the least status discrepancy among the non-healthy marriages. (2) Educational status discrepancy provides the sharpest differentiation 


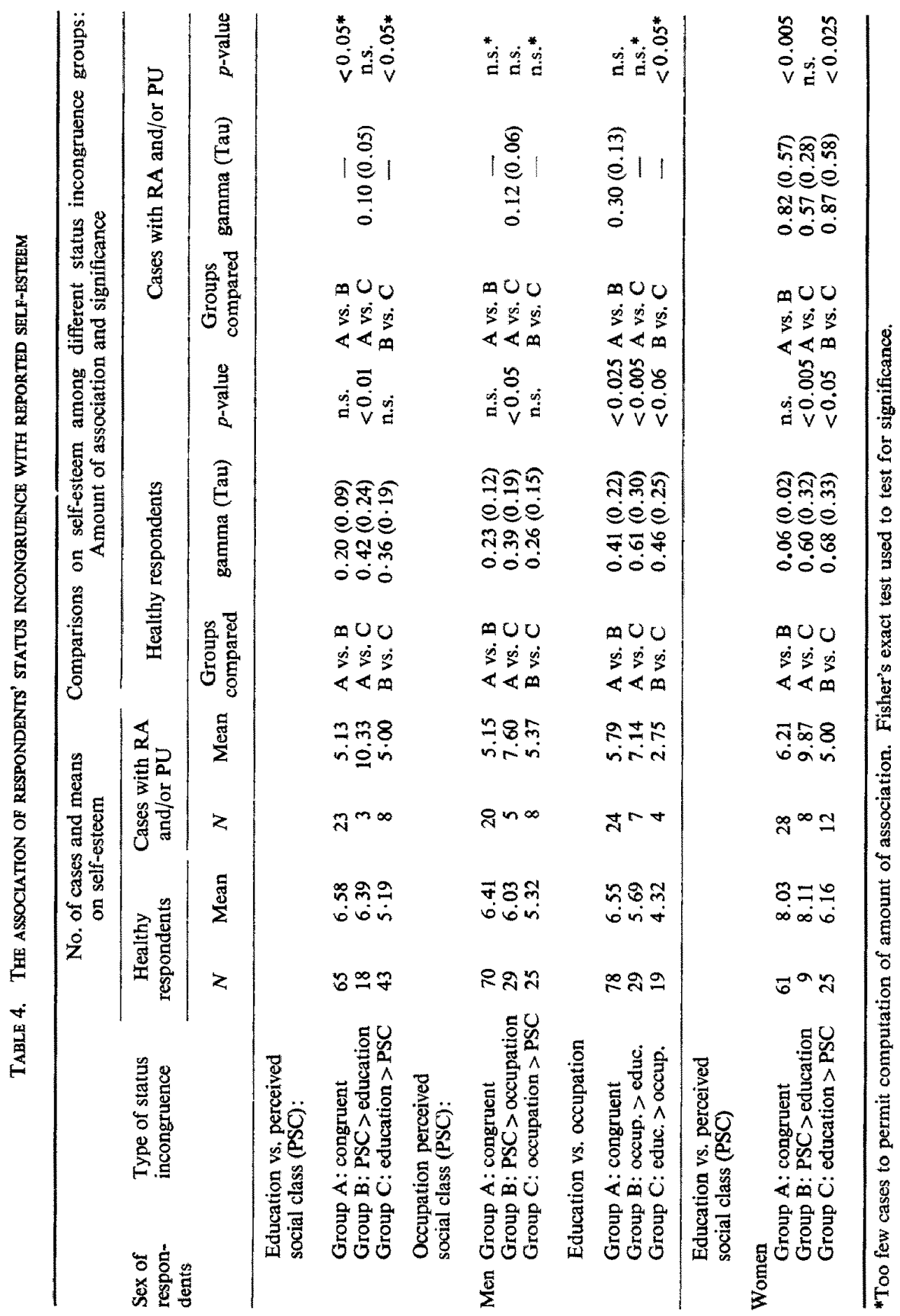




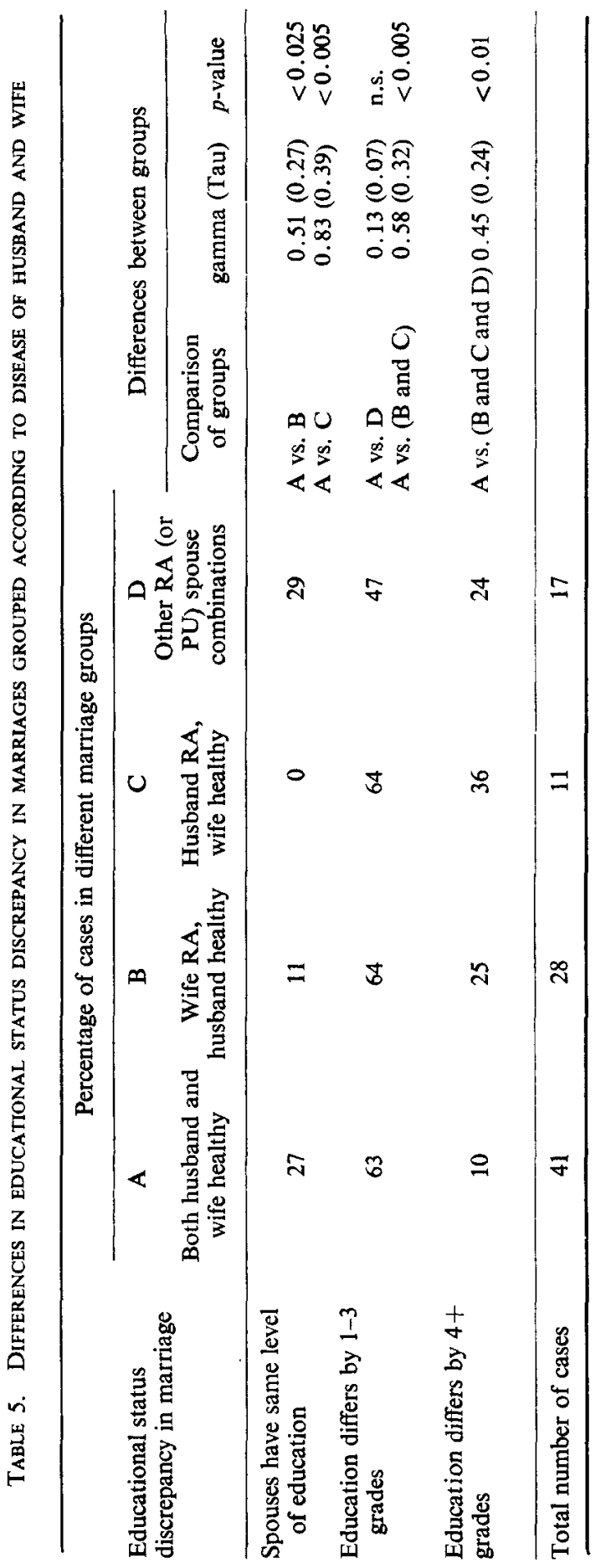




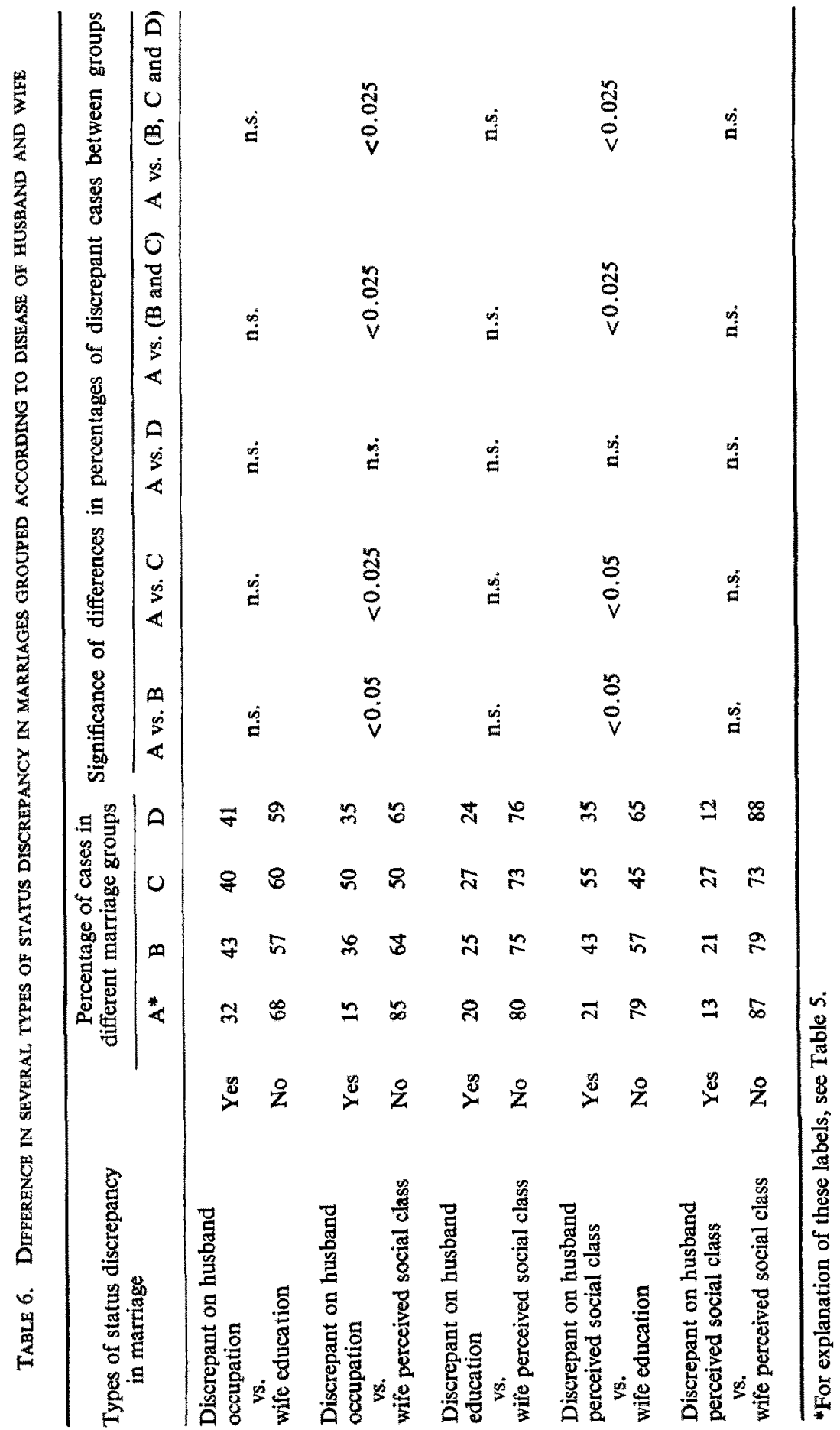


among the 4 groups. Also significant differences are found for "husband occupation vs. wife PSC' and 'husband PSC vs. wife education' types of discrepancy.

Table 7, which presents the association of total status discrepancy with disease in marriage, is another way of summarizing the findings in the previous two tables. The total index is roughly split into quartiles in order to show in a more detailed way the distribution of cases in the various marriage groups.

The status discrepancy measures in Tables 5-7 give no consideration to the direction

TABle 7. Differences ON TOTAL STATUS DISCREPANCY INDEX IN MARRIAGES GROUPED ACCORDING TO DISEASE OF HUSBAND AND WIFE AND ASSOCIATION OF STATUS DISCREPANCY IN MARRIAGE WITH SELF-ESTEEM OF SPOUSES

\begin{tabular}{|c|c|c|c|c|c|c|c|}
\hline \multirow{3}{*}{$\begin{array}{l}\text { Amount of discrepancy } \\
\text { on total status } \\
\text { discrepancy index }\end{array}$} & \multirow{2}{*}{\multicolumn{4}{|c|}{$\begin{array}{l}\text { Percent of cases in } \\
\text { different marriage groups }\end{array}$}} & \multicolumn{3}{|c|}{ Differences between groups } \\
\hline & & & & & \multirow{2}{*}{$\begin{array}{l}\text { Comparison } \\
\text { of groups }\end{array}$} & \multirow{2}{*}{ gamma (Tau) } & \multirow{2}{*}{$p$-value } \\
\hline & $A^{*}$ & $\mathbf{B}$ & $\mathbf{C}$ & $\mathbf{D}$ & & & \\
\hline Very high & $\mathbf{0}$ & 18 & 30 & 18 & A vs. B & $0.68(0.43)$ & $<0.001$ \\
\hline High & 24 & 43 & 30 & 29 & A vs. C & $0.70(0.37)$ & $<0.01$ \\
\hline Moderate & 37 & 32 & 20 & 6 & A vs. D & $0.47(0.25)$ & $<0.05$ \\
\hline Low & 39 & 7 & 20 & 47 & A vs. $(B \& C)$ & $0.65(0.41)$ & $<0.001$ \\
\hline Total number of cases & 38 & 28 & 10 & 17 & A vs. (B\&C\&D) & $0.61(0.34)$ & $<0.001$ \\
\hline
\end{tabular}

\begin{tabular}{|c|c|c|c|c|}
\hline \multirow{2}{*}{$\begin{array}{l}\text { Association of self- } \\
\text { esteem with }\end{array}$} & \multicolumn{2}{|c|}{ Husbands $(N=93)$} & \multicolumn{2}{|c|}{ Wives $(N=93)$} \\
\hline & gamma (Tau) & $p$-value & gamma (Tau) & $p$-value \\
\hline $\begin{array}{l}\text { Educational status } \\
\text { discrepancy }\end{array}$ & $-0.11(-0.07)$ & n.s. & $-0.42(-0.26)$ & $<0.005$ \\
\hline $\begin{array}{l}\text { Total status } \\
\text { discrepancy Index }\end{array}$ & $-0.28(-0.14)$ & n.s. & $-0.50(-0.28)$ & $<0.005$ \\
\hline
\end{tabular}

*For explanation of these labels, see Table 5.

of the discrepancy; e.g., in Table 5, the scoring ignores which spouse is higher on education. In point of fact, another set of indices, parallel to those used in Tables 5-7, but now scoring for the direction of discrepancy, was constructed. None of these directional status discrepancy measures differentiated the 4 marriage groups.

Table 7 also presents the data which relate the self-esteem of the spouses to 2 indices of status discrepancy, the education difference and the total summary index. For both spouses the association is a negative one: low self-esteem is found among respondents from status discrepant marriages. However, for the husbands the association is weak and not significant; among the wives, the relationship is fairly strong. This sex differential in status discrepancy effects is not inconsistent with the notion that in our society marriage for women is a more important source of role definitions and self definitions than it is for men and that, therefore, status discrepancy in marriage would be more disruptive to women than to men.

Let us finally turn to an examination of the possible effects husband's own status incongruence may have on physical health and self-esteem of the wife. For this purpose, three incongruence indices were used: husband's education vs. his occupation, husband's education vs. his income, and his occupation vs. his income. The reader will note that unlike the indices in Table 3, income rather than perceived social class is 
used in pairing it with education and occupation. This was done because it was assumed that such a set of indices would be more relevant for the present purpose of examining the possible effects on the wife. It should be also noted that in order to carry out our purpose, we want to compare marriages where both spouses are healthy (Group A) with those where the husband is healthy but the wife has RA (Group B). In this way, the health of the wife is the only point of contrast.

The relevant data are given in Table 8. It can be seen that the marriages where the husband is incongruent on the selected paired status dimensions are more likely to include wives with RA than marriages where the husband is congruent on such dimensions. The association between wife's disease and a total index describing husband's incongruence is particularly strong. It is also of great interest to note that husband's incongruence affects wife's self-esteem. Wives married to status incongruent husbands (as measured by the total summary index) have lower selfesteem: gamma $=-0.61, \mathrm{Tau}=-0.33, p<0.001$. (This particular association with self-esteem was computed for all 95 wives, since here we are not interested in the health status of the spouses.)

TABLE 8. RELATIONSHIP OF HUSBAND'S OWN STATUS INCONGRUENCE TO DISEASE IN WIFE

\begin{tabular}{|c|c|c|c|c|c|}
\hline \multirow{2}{*}{$\begin{array}{l}\text { Type of husband's } \\
\text { status incongruence }\end{array}$} & \multicolumn{3}{|c|}{ Percentage of cases in marriage groups } & \multirow{2}{*}{\multicolumn{2}{|c|}{$\begin{array}{l}\text { Significance of } \\
\text { difference in } \\
\text { percentages }\end{array}$}} \\
\hline & $\begin{array}{r}\text { Both } \\
\text { wif }\end{array}$ & $\begin{array}{l}\text { ausband and } \\
\text { healthy }\end{array}$ & $\begin{array}{l}\text { Wife RA, } \\
\text { husband healthy }\end{array}$ & & \\
\hline \multirow{2}{*}{$\begin{array}{l}\text { Husband incongruent } \\
\text { on education } \\
\text { vs. } \\
\text { income }\end{array}$} & Yes & 25 & 64 & \multirow{2}{*}{\multicolumn{2}{|c|}{$<0.005$}} \\
\hline & No & 75 & 36 & & \\
\hline \multirow{2}{*}{$\begin{array}{l}\text { Husband incongruent } \\
\text { on occupation } \\
\text { vs. } \\
\text { income }\end{array}$} & Yes & 15 & 61 & \multirow{2}{*}{\multicolumn{2}{|c|}{$<0.001$}} \\
\hline & No & 85 & 39 & & \\
\hline \multirow{3}{*}{$\begin{array}{l}\text { Husband incongruent } \\
\text { on education } \\
\text { vs. } \\
\text { occupation }\end{array}$} & Yes & 25 & 39 & \multirow{2}{*}{\multicolumn{2}{|c|}{ n.s. }} \\
\hline & No & 75 & 61 & & \\
\hline & & & & gamma (Tau) & p-value \\
\hline \multirow{4}{*}{$\begin{array}{l}\text { Amount of husband's } \\
\text { total incongruence }\end{array}$} & High & 2 & 14 & \multirow{4}{*}{\multicolumn{2}{|c|}{$0.68(0.45)$}} \\
\hline & Moderate & 25 & 46 & & \\
\hline & Low & 9 & 29 & & \\
\hline & None & 65 & 11 & & \\
\hline Total number of cases & & 40 & 28 & & \\
\hline
\end{tabular}

\section{DISCUSSION}

Let us begin with an overview of the findings just presented. Women with RA are more likely to come from families where the parents' marriage is status discrepant and the father is incongruent on education vs. occupation. Men with RA show a weak 
trend in the opposite direction: they are somewhat less likely to come from such families. Status incongruence of the respondents themselves bore no relationship to RA, either in men or women. However, when the marriages of the respondents were characterized according to status discrepancy, reliable differences were found: marriages where both spouses are healthy are much less likely to be status discrepant than those marriages where one of the spouses (either the man or the woman) had RA and the other spouse is healthy. Also interesting was the finding that healthy husbands who were status incongruent were more likely to have wives with RA than healthy husbands who were status congruent.

In passing it is of some interest to note that ulcer cases in men (those scoring 'definite' on the PU index) were not significantly different from men without ulcers or status inconsistency of parents or their own status incongruence.

It should be also noted that the association between RA in wife and either marital status discrepancy or husband's status incongruence (Tables 7 and 8 ) is the strongest when the husband is healthy: marriages where the RA wife has a husband with RA and/or PU (12 cases in Group D) are significantly lower on marital discrepancy and husband's incongruence than the wife RA-husband healthy (Group B) marriages.

When the respondents' self-esteem was examined as the second dependent variable, the following findings were obtained: Both men and women who come from families where the parents' marriage is status inconsistent report lower self-esteem. Status incongruence of the respondents themselves is also related to self-esteem: congruent men and women have generally the highest self-esteem while those incongruent cases whose education is "inappropriately" high have the lowest self-esteem. Status discrepant marriages have wives with lower self-esteem; the effect on the husbands is in the same direction but is not significant. Finally, wives married to status incongruent husbands have lower self-esteem than those married to status congruent men.

The first point which should be raised in this discussion concerns the interrelationship among the various status inconsistency measures. Our concern here is that if some of them are very highly intercorrelated, then, of course, the associations with RA and self-esteem shown in the various tables do not reflect wholly independent effects. The 'total parental status stress index' is not significantly associated with any of the other indices and, therefore, its effects are independent of the effects of any other type of inconsistency.

Two of the three status incongruence indices computed on the men are positively intercorrelated: Educ. vs. Occup. with Occup. vs. PSC (gamma $=0.51$, Tau $=0.26$ ) and Educ. vs. PSC with Occup. vs. PSC (gamma $=0.41, T a u=0.21$ ). But since neither of these, nor the third one, is related to RA (Table 3), this overlap among the measures is of little consequence. The situation is different in Table 7 where the associations with self-esteem are significant; for this table the reader must be reminded that the associations reflect the contribution of three overlapping rather than independent measures. When these three status incongruence indices (on men) are correlated with the 'total marriage status discrepancy index', only one of them, Educ. vs. Occup., shows a significant association (gamma $=0.37, \mathrm{Tau}=0.23$ ). However, since this index is uncorrelated with RA, it cannot be contributing to the high marital discrepancy found in Group C marriages (Table 7).

The Educ. vs. PSC status incongruence measure computed on women is significantly associated with the marital discrepancy index $($ gamma $=0.55, T a u=0.34)$. 
However, this measure, as in the case of the men, is again not significantly associated with RA (Table 3) and thus cannot be contributing to the high marital status discrepancy found in Group B marriages (Table 7). But since both measures are associated with self-esteem (Tables 4 and 7), it seems that we should recompute the association between self-esteem and marital discrepancy (gamma $=-0.50$ ) by holding constant the effects of Educ. vs. PSC incongruence. This can be done by calculating a partial gamma according to a procedure described by DAvIS [30]. The obtained partial gamma is -0.63 , a value higher than the original one. This result is to be expected since only one direction of Educ. vs. PSC incongruence (Educ. $>$ PSC) is associated with low self-esteem, while both forms of Educ. vs. PSC incongruence are more frequent in the high marital discrepancy cases.

Finally, it was found that the 'total marriage status discrepancy index' is significantly related (gamma $=0.50, \mathrm{Tau}=0.38$ ) to the measure of husband's total incongruence (Table 8). Thus it is possible that the association of husband's incongruence with wife's RA (gamma $=0.68$ ) and with her self-esteem (gamma $=-0.61$ ) is partly a spurious one, accounted for by the influence of marital discrepancy on RA and self-esteem (Table 7) and by the association between marital discrepancy and husband's incongruence. However, when partial gammas are computed, holding the effect of marital discrepancy constant, the gamma values remain practically unchanged: gamma $=0.62$ for association with wife's RA and gamma $=-0.64$ for association with wife's self-esteem.

The second point to be raised in this discussion concerns the construction of the various status inconsistency indices and the data analysis methods. It should be evident that the present indices are rather crude-especially those dealing with parental status inconsistency - and that they are ad hoc measures designed to serve the immediate purpose of exploring the data in the present study. As this type of work gets beyond the exploratory stages-provided the findings justify a continued interest in the area-it should be possible to begin using more standardized indices based upon some more general norms, perhaps national census data. A step in this direction has already been taken [31] and data are available on the association of status inconsistency with race, residence, and life cycle [32]. However, the use of national norms does not solve other existing problems. For example, which dimensions (status ranks) should be used in constructing the various inconsistency indices? Is race a good dimension or should one exclude race but construct separate indices for whites and Negroes [33, 34]? Another important question is: What is the relationship between objective and subjective (felt or perceived) inconsistency? Will subjective inconsistency differ systematically across different sub-populations? How much do we have to know about subjective inconsistency before we can construct meaningful indices?

Another important point in the construction of inconsistency indices concerns the issue of the direction of inconsistency and attendant differential effects. Given the imperfect articulation of status inconsistency theory and the uncertainty surrounding the choice of appropriate status variables, one needs to construct indices which will detect situations where high-low and low-high inconsistency are associated in opposite directions with a dependent variable. In the present study, the direction of inconsistency seemed in most instances to be unimportant. However, we wish to emphasize that while enough cases were involved to detect a global inconsistency 
effect, we certainly do not have enough cases to conclude that no differential effect within types of inconsistency exists. The apparent unimportance of direction of parental status inconsistency and marital status discrepancy must be confirmed, for a particular dependent variable, in future studies before one can ignore it in constructing a status inconsistency index.

It should be also noted that in the present study, the data analysis testing for inconsistency effects was relatively simple. This is because the dependent variables, RA and self-esteem, were not related to the several status variables, nor were the inconsistency indices themselves highly related. However, when vertical status itself has an effect on the dependent variable, the teasing out of the inconsistency effects becomes a difficult task. For a recent discussion of this analytical problem, the reader is referred to BLALOCK [35] and HyMAN [36].

The final point to be discussed concerns the general interpretive framework within which our findings may be placed. The meaning of parental status inconsistency has been explored in a previous report [28]; here, we shall merely note that the empirical tie-in with a number of variables related to RA-recalled arbitrary authority of parents, anger-irritation, depression, etc-is sufficiently good to justify the following speculative causal link: status stress in parents $\longrightarrow$ conflicting expectations and uncertainty about appropriate behavior as parent and spouse $\longrightarrow$ unsatisfactory relations between parents, and higher frustration $\longrightarrow$ arbitrary authority in treatment of same-sexed offspring $\longrightarrow$ child's poor identification with parents and feelings of rejection $\longrightarrow$ unstable or inadequate self-image and low self-evaluation as child and adult $\longrightarrow$ symptoms of poor physical and mental health. This set of relationships clarifies considerably the functional meaning of parental status inconsistency.

The role of the respondent's own status incongruence is less clear. On the one hand, it bears no reliable relationship to RA. On the other hand, it is clearly related to self-esteem, as well as a number of other variables broadly reflecting mental health (as revealed by preliminary analyses not presented in this report). The path of influence from status incongruence to symptoms of poor mental health-if that is the probable dominant direction of influence-is not apparent inasmuch as no data were collected about the possible intervening processes. However, the findings are fully compatible with the status inconsistency theory outlined at the beginning of this report.

Status discrepancy in marriage offers the possibility of the most complicated theoretical picture because of the uncertainty regarding the basic direction of influence. While in parental status inconsistency, because of its clear temporal location, we have a rather unambiguous antecedent variable, we are less certain about the direction of influence in status incongruence because of the possibility of mental health and associated changes altering status congruence. And even less certain are we about marital status discrepancy: here not only do we have the strong possibility of a certain type of person entering a certain kind of marriagc (c.g. the RA woman sccms to be in the same kind of a status discrepant marriage as that of her parents), but we also know that the spouse's behavior may always be an additional complicating variable. That is, it is unlikely that, for example, the association between marital discrepancy and RA in wife does not involve, at some point, the husband's behavior. It is worth noting that preliminary analyses indicate other correlates of marital status dis- 
crepancy: (a) Women in discrepant marriages are more depressed (gamma $=0.28$, $\mathrm{Tau}=0.19, p<0.05$ ); the association for men is in the same direction (gamma= 0.25 , Tau $=0.14$ ) but not significant. (b) Status discrepant marriages are characterized by high marital hostility (gamma $=0.48, \mathrm{Tau}=0.25, p<0.01$ ), as measured by the index developed in the seventh paper of this series. It would thus appear that many of the variables associated with RA are also associated with marital discrepancy and that, moreover, the effects are somewhat broader and stronger in the case of the wives than the husbands.

Let us conclude this discussion section with an indication of the strength of association which we have found between RA and the various status inconsistency measures. The reader will have to keep in mind, of course, that because of the design of the study, the base rates for RA among our subjects are quite different from the true population rates for rheumatoid arthritis, and the statements about the relative strength of association will therefore apply only to our subjects. Parental status stress has a negligible effect on rates of RA among men. Among women, the effect is strong: 20 per cent of those coming from low status stress families have RA; 40 per cent are with RA if they come from intermediate stress families, and the number is 68 per cent if they come from high stress families.

In assessing the effects of marital discrepancy, we shall compare 38 marital pairs without RA with 38 pairs where one or the other spouse has RA, but not both, and neither has PU. Among those low on marital discrepancy, 34 per cent of marriages have one spouse with RA; among those high on marital discrepancy, 72 per cent of marriages have one spouse with RA.

Finally, in looking at effects of husband's status incongruence on wife's RA, we can compare 40 pairs of marriages without RA with 28 marriages where the healthy husband is married to RA wife. Ten per cent of status congruent husbands have wives with RA whereas 64 per cent of status incongruent husbands have RA wives.

\section{SUMMARY}

This study examines the relationship of 2 focal variables, rheumatoid arthritis and self-esteem, to several types of status inconsistency: that of the parents, of the respondents themselves, and of the respondents' marriage. The RA cases came both from a national interview sample and a university arthritis clinic. Ths subjects without RA were part of a cluster which included the spouse of the RA, the RA's sib and his (her) spouse, a cousin of the RA, and an unrelated individual. The data were collected in the course of three structured interviews: The major findings were as follows:

(1) Women with RA are more likely to come from families where the parents' marriage is status discrepant and the father is incongruent on education vs. occupation.

(2) Men with RA are somewhat less likely to come from such status inconsistent families, while the frequency of men with PU was unrelated to parental inconsistency.

(3) Both men and women from status inconsistent families report lower self-esteem when describing themselves as adults.

(4) Several forms of status incongruence of the respondents themselves bore no relationship to RA in women and to RA or PU in men.

(5) Status incongruent men whose education was 'inappropriately' high in relation to their occupation or to their perceived social class (PSC) were particularly low on self-esteem, while congruent men were generally the highest. 
(6) Status incongruent women had the lowest self-esteem if their education exceeded their perceived social class, but highest self-esteem if their social class exceeded their education while congruent women were intermediate but closer to the latter group.

(7) Marriages where both spouses were healthy were less likely to be status discrepant than those marriages where one or the other of the spouses had RA.

(8) Wives in status discrepant marriages were more likely to have low self-esteem and more depression than wives where little or no discrepancy existed. The associations for the husbands were in the same direction but not significant.

(9) Status discrepant marriages were higher on marital hostility.

(10) Healthy husbands who were themselves status incongruent were more likely to have wives with RA than healthy husbands who were status congruent. Such wives had also lower self-esteem.

\section{REFERENCES}

1. CoOley, C. H.: Human Nature and the Social Order. Scribner's, New York, 1902.

2. Mead, G. H.: Mind, Self, and Society. University of Chicago Press, Chicago, 1934.

3. Gross, N. C., Mason, W. S. and McEACHERN, A. W.: Exploration in Role Analysis. Wiley, New York, 1958.

4. Sarbin, T. R.: Role theory, in Handbook of Social Psychology. Vol. I. (Ed. Lindzey, G.) Addison-Wesley, Cambridge, 1954.

5. FRENCH, J. R. P., JR, and KAHN, R. L.: A programmatic approach to studying the environment and mental health. J. soc. Issues 18, (3) 1, 1962.

6. Miller, D. R.: The study of social relationships: situation, identity, and social interaction. In: Psychology: A Study of a Science Vol. 5. (Ed. Koch, S.) McGraw-Hill, New York, 1963.

7. Benorr-Smullyan, E.: Status, status types, and status interrelations. Am. sociol. Rev. 9, 151, 1944.

8. Fenchel, G. E., Monders, J. H. and Hartley, E. L.: Subjective status and the equilibration hypothesis. J. abnorm. soc. Psychol. 46, 476, 1951.

9. LENSKI, G.: Status crystallization: A non-vertical dimension of social status. Am. sociol. Rev. 19, $405,1954$.

10. BROOM, L.: Social differentiation and stratification. In: Sociology Today. (Eds NorTon, R. K., Broom, L. and CotTrell, L. S., JR.). Basic Books, New York, 1959.

11. JACKSON, E. F.: Status consistency and symptoms of stress. Am. sociol. Rev. 27, 469, 1962.

12. SAMPSON, E. E.: Status congruence and cognitive consistency. Sociometry 26, 146, 1963.

13. Homans, G. C.: Social Behavior: Its Elementary Forms. Harcourt, Brace \& World, New York, 1961.

14. Adams, S.: Status congruency as a variable in small group performance. Social Forces 32, 16, 1953.

15. Burnstein, E. and Zajonc, R. B.: The effect of group success on the reduction of status incongruence in task-oriented groups. Sociometry 28, 349, 1965.

16. ExLINE, R. V. and ZILLER, R. C.: Status congruency and interpersonal conflict in decisionmaking groups. Hum. Relat. 12, 147, 1959.

17. Hodge, R. W.: The status consistency of occupational groups. Am. sociol. Rev. 27, 336, 1962.

18. JACKSON, E. F. and BuRKE, P. J.: Status and symptoms of stress: additive and interaction effects. Am. sociol. Rev. 30, 556, 1965.

19. KING, S. H. and CoBb, S.: Psychosocial factors in the epidemiology of rheumatoid arthritis. J. chron. Dis. 7, 466, 1958.

20. Goffman, I. W.: Status consistency and preference for change in power distribution. Am. sociol. Rev. 22, 275, 1957.

21. LENSKI, G.: Social participation and status crystallization. Am. sociol. Rev. 21, 458, 1956.

22. KornhauSer, A.: Mental Health of the Industrial Worker. Wiley, New York, 1965.

23. ManN, F. C.: A Study of Work Satisfaction as a Function of the Discrepancy Between Inferred Aspirations and Achievement. Unpublished doctoral dissertation, University of Michigan, 1953.

24. Parker, S. and KLeiner, R. J.: Mental Illness in the Urban Negro Community. The Free Press, New York, 1966.

25. Floud, J. E., MARTIN, F. M. and HALSEY, A. H.: Educational opportunity and social selection in England. In: Transactions of the Second World Congress of Sociology, Vol. 2. International Sociological Association, London, 1954. 
26. KRAUSS, I.: Sources of educational aspirations among working-class youth. Am. sociol. Rev. 29, 867, 1964.

27. Morgan, J. N., David, M. H., Cohen, W. J. and Brazer, H. E.: Income and Welfare in the United States. McGraw-Hill, New York, 1962.

28. KASL, S. V. and COBB, S.: Effects of parental status incongruence and discrepancy on physical and mental health of adult offspring. I. Personality soc. Psychol. Monogr. 7, 1, No. 2 (Whole No. 642), 1967.

29. Reiss, A. J., JR. (Ed.): Occupations and Social Status. Appendix B. The Free Press, Glencoe, Ill., 1961.

30. DAVIS, J. A.: A partial coefficient for Goodman and Kruskal's gamma. J. Am. Stat. Ass. 62, $189,1967$.

31. U.S. Bureau of THE Census: Methodology and scores of socioeconomic status. Working Paper No. 15. Washington, D.C., 1963.

32. Nam, C. B. and Powers, Mary G.: Variations in socioeconomic structure by race, residence, and the life cycle. Am. sociol. Rev. 30, 97, 1965.

33. KenKEL, W. F.: The relationship between status consistency and politico-economic attitudes. Am. suciol. Rev. 21, 365, 1956.

34. Mrrchell, R. E.: Methodological notes on a theory of status crystallization. Pub. Opin. $Q$. 28, 315, 1964.

35. BLALOCK, H. M., JR.: Status inconsistency, social mobility, status integration and structural effects. Am. sociol. Rev. 32, 790, 1967.

36. Hyman, M. D.: Determining the effects of status inconsistency. Publ. Opin. Q. 30, 120, 1966. 